\title{
PARA O $2^{\circ}$ ANO DO
}

ENSINO FUNDAMENTAL

Juliana Anhel Cidade Cardoso

Pontifícia Universidade Católica de Minas Gerais - PUC Minas Virtual.

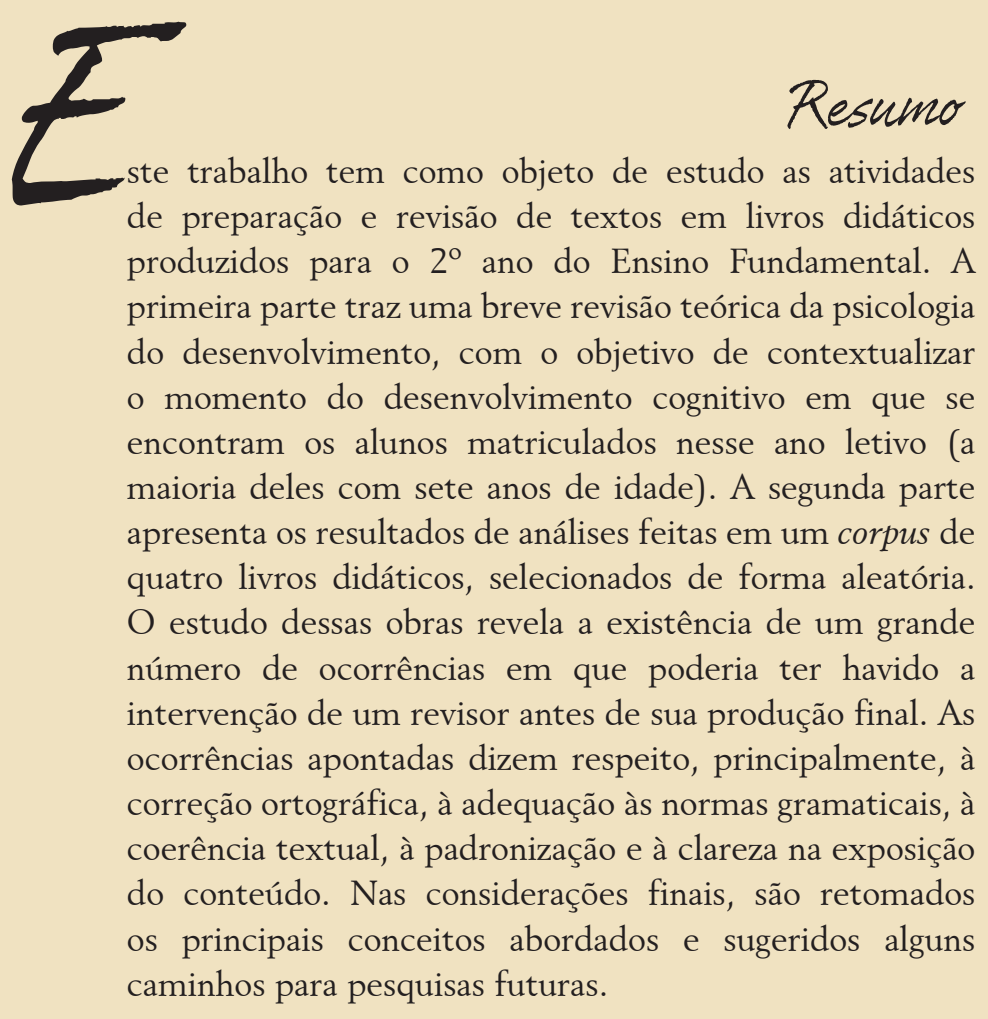

Palavras-chave: Revisão textual. Materiais didáticos. Desenvolvimento humano.

Esta pesquisa teve como ponto de partida o interesse em investigar a atividade de revisão de textos em livros didáticos do $2^{\circ}$ ano do Ensino Fundamental.

A escolha de ter como objeto de pesquisa livros didáticos deveu-se ao fato de serem materiais de grande importância para o aprendizado, tanto em sala de aula quanto nos estudos que os alunos fazem em casa. O livro didático é ferramenta 
fundamental para o trabalho que os professores desenvolvem com suas turmas, servindo como um norte sequencial e metodológico e influenciando profundamente o processo ensino-aprendizagem.

O recorte feito para definir o ano letivo a ser estudado deveu-se, sobretudo, ao fato de que o $2^{\circ}$ ano do Ensino Fundamental é o primeiro da vida escolar após a alfabetização e, consequentemente, o primeiro ano em que habilidades tais como leitura, interpretação, atendimento correto ao enunciado ou comando serão exigidas do aluno de maneira mais contundente; e assim será para o resto de sua vida escolar. Para que os estudantes possam responder a essas exigências de maneira adequada é preciso contar com um material de apoio de excelência.

Mas o que configura essa desejada excelência em um livro didático? Segundo o Programa Nacional do Livro Didático (PNLD), "o livro didático deve veicular informação correta, precisa, adequada e atualizada" (BRASIL, 2012, p. 9). O PNLD traz ainda algumas orientações aos professores para que avaliem os livros didáticos que adotam, fazendo - para si próprios - algumas perguntas, tais como: "A linguagem é clara e precisa?", "O texto das explicações é acessível para os alunos?" e "As atividades se preocupam em ajudar o aluno a entender o texto das lições?" (BRASIL, 2012, p. 11).

Pode-se concluir que, apesar de não mencionar especificamente a atividade de revisão de textos, o Ministério da Educação (MEC) reconhece a necessidade de que os livros didáticos apresentem textos que estejam de acordo com a gramática normativa (ora, o que seria "linguagem clara e precisa" em se tratando de educação escolar formal?), que sejam coerentes, padronizados, sem erros de digitação ou diagramação (vide a orientação de que o texto das explicações seja acessível para os alunos) e que proponham questões, atividades e tarefas através de enunciados e comandos claros, precisos, sem ambiguidades e que retomem adequadamente conceitos estudados nas lições (vide a orientação de que as atividades se preocupem em ajudar $\mathrm{o}$ aluno a entender os textos).

Uma vez que a tarefa de garantir que um livro didático atenda aos parâmetros de qualidade determinados pelo MEC não cabe somente ao autor, mas também à equipe de preparadores e revisores, é de grande relevância estudar de que maneira o trabalho de revisão desse livro está sendo realizado em 


\section{alemens

1 As informações completas sobre as obras estudadas podem ser encontradas nas Referências, ao final deste artigo. diferentes editoras brasileiras. Para isso, apresentaremos neste artigo os resultados de análises feitas em um corpus de quatro livros didáticos do $2^{\circ}$ ano do Ensino Fundamental.

Os livros selecionados para análise neste artigo são: Na Ponta da Língua (Access Editora), Redescobrindo o Universo Religioso (Editora Vozes), Aprender Juntos Ciências (Edições SM Ltda.) e Buriti História (Editora Moderna). ${ }^{1}$ A metodologia utilizada para análise consistiu na revisão de todas as páginas de cada livro, a fim de verificar se existiam ocorrências que poderiam ter sido tratadas por um preparador ou revisor antes da produção final do livro. É importante ressaltar que as ocorrências dizem respeito a qualquer observação que um profissional de textos pudesse ter feito para contribuir para o aperfeiçoamento da obra, e não necessariamente a erros ortográficos ou gramaticais. Para cada ocorrência verificada foi oferecida uma sugestão de intervenção e, em seguida, as sugestões foram divididas em categorias, conforme sua natureza. Na sequência, os dados levantados foram analisados e os resultados da análise serão apresentados neste artigo.

Por fim, é necessário trazer também uma reflexão a respeito do público consumidor do produto que estamos estudando (alunos do $2^{\circ}$ ano do Ensino Fundamental, ou seja, crianças com aproximadamente sete anos de idade). Quando afirmamos que um texto deve ser claro, preciso, adequado e acessível, precisamos nos perguntar para quem. Certamente haverá necessidades específicas e pontuais de cada faixa etária em relação ao consumo de livros didáticos. Os livros produzidos para a Educação Infantil serão diferentes dos produzidos para o Ensino Fundamental, que serão diferentes dos produzidos para o Ensino Médio e daí por diante. Mesmo dentro de um mesmo segmento, haverá diferentes especificidades de acordo com o ano letivo. Portanto, para enriquecer a discussão neste artigo, realizaremos uma breve revisão teórica da psicologia do desenvolvimento, com enfoque na faixa etária padrão dos alunos do $2^{\circ}$ ano do Ensino Fundamental (os sete anos de idade).

\section{A criança de sete anos}

Muitos estudiosos de diversas áreas já se debruçaram sobre o tema dos estágios do desenvolvimento humano. Faz parte do senso comum o entendimento de que as crianças pensam, agem e se relacionam de forma diferente de como fazem os adultos, passando por vários momentos durante a infância. Quando 
bebês, ainda não falam e dependem exclusivamente dos cuidados dos adultos para sobreviver. Por volta dos dois anos, com a aquisição da linguagem, há um salto no desenvolvimento cognitivo, pois ela passa a conseguir se comunicar, realizando a desafiadora tarefa de traduzir em palavras aquilo que pensa e sente. A partir daí o processo de socialização pode iniciar-se de forma plena e novos estágios de desenvolvimento cognitivo são alcançados.

Um dos mais relevantes pesquisadores para o campo do desenvolvimento humano foi Jean Piaget. O epistemólogo suíço desenvolveu diversos estudos e teorias, que foram base para muitas pesquisas posteriores e que são considerados importantes por profissionais da área até hoje.

Em seu livro O Juízo Moral na Criança, Piaget trata, basicamente, dos conceitos relativos às construções feitas pelas crianças sobre as noções de regra e justiça, a partir de diversas entrevistas realizadas com elas. Embora o tema central do livro não seja, propriamente, o deste artigo, algumas das ideias contidas nessa obra são particularmente relevantes para embasar este estudo.

Quando Piaget trata do desenvolvimento moral na criança, aborda as diferentes fases pelas quais ela passa em relação à consciência eà prática das regras. A primeira delas seria a anomia, em que há uma ausência de regras em seu entendimento, ou seja, as crianças pequenas ainda não conseguem assimilar e obedecer às regras, de uma maneira geral.

Em um segundo momento, na heteronomia, a criança começa a ser capaz de interiorizar as regras propostas (ou impostas) pelos adultos ou até mesmo por outras crianças, em geral mais velhas, especialmente na prática de jogos sociais. Nesse estágio, ela entende a regra como algo que vem do outro, sem que ela faça parte da construção dessas regras. Aqui, a criança não entende a regra ainda como uma real necessidade relativa a um contexto, mas é capaz de respeitá-la através da noção de autoridade de quem a propõe ou impõe.

Somente mais tarde é que a criança conseguirá caminhar rumo à autonomia (terceiro estágio do desenvolvimento moral), no qual ela entenderá que existe a necessidade de regras para se viver em sociedade e que ela mesma pode participar desse processo, colaborando ativamente com a construção das regras que ela própria precisará seguir. Nas palavras de Piaget: 
2 Ressalta-se aqui que os livros didáticos com os quais as crianças trabalham nas escolas estão repletos de imperativos oferecidos pelos adultos (para usar as mesmas palavras de Piaget). Esses imperativos encontram-se, por exemplo, nos enunciados e nos comandos das tarefas propostas, em diversos momentos ao longo de todos os livros analisados neste artigo.
Do ponto de vista psicológico, a mesma regra constitui, totalmente, uma outra realidade para a criança de sete anos, que a considera como sagrada e intocável, e para a criança de doze anos, a qual, sem chegar a isso, só a considera como válida, depois do mútuo consentimento (PIAGET, 1994, p. 83).

Ora, e no que tal reflexão relativa à noção de regras pode contribuir no entendimento das crianças da faixa etária do nosso estudo? Ocorre que, estando as crianças de sete anos ainda na fase da heteronomia, entendem e respeitam as regras que lhes são impostas pelos adultos; mas pode ser que não consigam ainda formular grandes questionamentos ou que não tenham a capacidade crítica e a postura ativa de colaboração, próprias da autonomia.

Encontramos ainda, na obra de Piaget, outras afirmações importantes para nossa análise, tais como: "Do ponto de vista intelectual, o respeito da criança pelo adulto tem por efeito provocar o aparecimento de uma concepção anunciadora da noção de verdade [...]” (PIAGET, 1994, p. 298); “[...] a criança [...] acredita, sem discussão, em tudo o que lhe contamos, em lugar de perceber no pensamento adulto o que ele admite de pesquisa e ensaio" (PIAGET, 1994, p. 298) e "Do mesmo modo como a criança crê na onisciência do adulto, igualmente acredita, sem mais, no valor absoluto dos imperativos recebidos" 2 (PIAGET, 1994, p. 299).

Assim sendo, se as crianças enxergam os adultos como autoridades máximas, respeitando as regras impostas por eles através de processos coercitivos, podemos deduzir que - de maneira análoga - as crianças enxergarão também os produtos oferecidos pelos adultos para seu processo de aprendizagem escolar como perfeitos, plenos, acabados. É desta forma que enxergarão seus livros didáticos, uma vez que foram adotados pela escola, comprados ou, ao menos, aceitos pelos pais e são trabalhados em sala de aula pelo professor. Podemos perceber, através das palavras do próprio Piaget e de suas ideias aqui expostas, que a criança dificilmente terá uma postura crítica em relação ao material fornecido para dar sustentação ao seu desenvolvimento intelectual, com o qual, necessariamente, tem que trabalhar.

É possível constatar então, mais uma vez, a importância da busca pela excelência em livros didáticos voltados para as crianças, especialmente levando-se em conta que a maioria delas não terá a capacidade de avaliar de maneira autônoma o 


\title{
aldenos

material que lhe é oferecido. Faz-se necessário refletir, ainda, se inadequações encontradas em livros didáticos para crianças podem prejudicar seu aprendizado, uma vez que elas não conseguirão perceber e indicar possíveis problemas e poderão tomá-las como o correto, o que deve ser aprendido, assimilado e imitado, em termos tanto conceituais quanto estruturais.

Outro importante teórico do campo do desenvolvimento humano foi L. S. Vigotski. Suas ideias são relevantes para este artigo uma vez que ele "[...] estava primeiramente preocupado em entender as origens do conhecimento da criança" (BEE; BOYD, 2011, p. 37). Nas palavras de Bee e Boyd:

\begin{abstract}
Vygotsky [...] estava convencido de que formas complexas de pensamento têm suas origens em interações sociais. [...] A aprendizagem de novas habilidades cognitivas é conduzida por um adulto (ou por uma criança mais hábil, como um irmão mais velho), que modela e estrutura a experiência de aprendizagem da criança $[\ldots]$. Essa nova aprendizagem, Vygotsky sugeriu, é melhor alcançada no que ele chamou de zona de desenvolvimento proximal - aquela gama de tarefas que são muito difíceis para a criança fazer sozinha, mas que ela pode conseguir com orientação. À medida que a criança se torna mais hábil, a zona de desenvolvimento proximal amplia-se constantemente, incluindo tarefas sempre mais difíceis. Vygotsky acreditava que a chave para esse processo interativo estava na linguagem que o adulto usa para descrever ou estruturar a tarefa. Posteriormente, a criança poderia usar essa mesma linguagem para orientar suas tentativas independentes de fazer os mesmos tipos de $\operatorname{tarefas}^{3}$ (BEE; BOYD, 2011 p.37).
\end{abstract}

3 Cabe esclarecer aqui que o último nome do teórico Liev Semiónovitch Vigotski é comumente grafado de maneiras distintas, em obras distintas. Para este artigo, optou-se pela grafia "Vigotski", que consta no livro "Pensamento e Linguagem", escrito pelo próprio (para mais informações sobre a obra, consultar as Referências). No entanto, o sobrenome do autor é grafado, no livro ora citado, como "Vygotsky".

Tendo também como base essas ideias de Vigotski, podemos novamente concluir que a linguagem apresentada pelos livros didáticos pode ser assimilada pelas crianças (no caso específico deste estudo, crianças em torno dos sete anos de idade) como a maneira correta de se produzir intelectualmente de acordo com os padrões definidos pela nossa educação formal.

Ora, se a linguagem - no caso dos livros didáticos, a linguagem escrita - que o adulto usa para descrever e estruturar a tarefa é a mesma que o aluno irá usar em suas tentativas posteriores de produção intelectual independente, é possível perceber a real necessidade de se produzir materiais didáticos para crianças que tenham padrão de excelência nos vários aspectos textuais. É através do processo de assimilação da linguagem aprendida 


\section{aldenos

nessa interação com o adulto que a criança estruturará as bases para seu próprio desenvolvimento intelectual quando for realizar as tarefas propostas, seja em sala de aula ou em casa; quando for fazer os testes, trabalhos avaliativos e provas; quando for produzir ou interpretar textos etc.

É importante considerar ainda que, nos primeiros anos do Ensino Fundamental, as crianças estão sendo apresentadas, pouco a pouco, à variedade de prestígio da língua. $\mathrm{O}$ bom manejo da linguagem formal, culta ou de prestígio dará liberdade para que a criança possa, futuramente, circular por diferentes esferas da nossa sociedade e optar por que tipo de linguagem usar, de acordo com o ambiente, as pessoas envolvidas e a ocasião. ${ }^{4}$

4 O conceito de "linguagem de prestígio", tão amplo e interessante, poderia ser tema de diversos outros artigos. Para este, faz-se necessário ressaltar, ao menos, que o ensino da "linguagem de prestígio", em todas as escolas, é ferramenta fundamental para a consolidação e a manutenção de uma sociedade verdadeiramente democrática.
Sendo assim, se o ofício de revisão e preparação de textos já exige, em qualquer circunstância, que o profissional realize um trabalho absolutamente minucioso, detalhista e baseado em pesquisa e recorrente consulta a fontes diversas, a responsabilidade do revisor de livros didáticos editados para os primeiros anos do Ensino Fundamental é ainda maior.

Um adulto, quando lê ou estuda por um livro, espera encontrar, evidentemente, um texto isento de erros ortográficos ou gramaticais e que tenha uma linguagem clara, de fácil entendimento. No entanto, se isso não acontece - e esse adulto teve uma boa educação formal - ele terá capacidade crítica para perceber os problemas do texto. Poderá, portanto, deixar o livro de lado e buscar outras fontes de conhecimento. Na pior das hipóteses, se precisar ler o livro até o fim - por razões profissionais ou acadêmicas, por exemplo - terá algum discernimento do conteúdo a ser aproveitado e daquele que deve ser descartado por estar ininteligível ou por apresentar muitos erros.

Já a criança tem suas novas habilidades cognitivas moldadas e estruturadas pelo adulto que conduz o processo de aprendizagem. Como visto anteriormente, para Vigotski, "a chave para esse processo interativo está na linguagem que o adulto usa para descrever ou estruturar a tarefa" (BEE; BOYD, 2011, p.37).

Portanto, pode-se perceber que as ideias de Vigotski corroboram a noção de que um livro didático com problemas conceituais e de coerência, erros ortográficos e gramaticais e que não estruture de forma padronizada seu conteúdo poderá prejudicar sim o processo de aprendizagem dos alunos, o que é muito ruim especialmente porque o objetivo desse material é justamente o contrário. 
Para ampliar a discussão, serão apresentados a seguir os resultados das análises feitas em quatro livros didáticos do $2^{\circ}$ ano do Ensino Fundamental, com o objetivo de verificar se existem problemas nesses materiais que poderiam, eventualmente, ter sido evitados pelo trabalho cuidadoso de um profissional de textos.

\section{Análise do corpus}

Para a realização desta pesquisa, foram estudados quatro livros didáticos de diferentes disciplinas, todos do $2^{\circ}$ ano do Ensino Fundamental. A escolha desses livros foi aleatória, pois o objetivo não era analisar obras específicas e sim verificar se existem ou podem existir problemas em relação à revisão de textos nesse tipo de material, qual a natureza desses problemas e, então, organizar os dados, de modo a oferecer uma análise que pudesse elucidar alguns pontos e levantar outros, para discussão.

A primeira fase do estudo consistiu no levantamento de dados, realizado através da revisão de todas as páginas de cada livro. Nesta etapa, todas as ocorrências encontradas foram registradas em um documento. Posteriormente foram registradas também, no mesmo documento, sugestões de intervenção para cada uma delas. Em seguida, as sugestões de intervenção para as ocorrências encontradas foram organizadas e separadas em categorias.

\section{DESCRIÇÃO DAS CATEGORIAS E SEUS EXEMPLOS}

\section{Sugestões relacionadas à ortografia}

Faz-se necessário ressaltar aqui que um grande percentual das ocorrências relativas a esta categoria dizem respeito a problemas relacionados à pontuação. Em alguns poucos casos, uma ou outra palavra foi grafada de fato de forma errada. De qualquer maneira, o único problema que pode ser considerado crítico em relação à ortografia é a pontuação, especialmente no que se refere ao uso de vírgulas. Seguem abaixo alguns exemplos de problemas relacionados à ortografia que foram encontrados nos livros analisados: 
- Exemplo 1 - No livro Na Ponta da Língua, p. 78, temos: "Chapeuzinho pára e colhe flores". De acordo com o Novo Acordo Ortográfico, a palavra "para" não deveria estar acentuada. É muito importante editar todo o livro conforme o Novo Acordo, principalmente para essa faixa etária, que já foi alfabetizada de acordo com as novas regras e sequer conhece como era antes. Apresentar palavras grafadas de maneira errada pode confundi-los bastante.

- Exemplo 2 - No livro Redescobrindo o Universo Religioso, p. 15, temos: "Puxa filho, agora com sete meses você já está pronto para sua primeira alimentação solene sólida!”. A palavra "filho" é vocativo e deveria aparecer entre vírgulas. Deve-se inserir, portanto, uma vírgula após a palavra "Puxa", que inicia a frase.

- Exemplo 3 - Para ensinar às crianças sobre habitat, essa palavra aparece no livro Aprender Juntos Ciências, a partir da página 49, grafada com acento (hábitat). No entanto, a palavra "habitat" está listada no VOLP (Vocabulário Ortográfico da Língua Portuguesa, da Academia Brasileira de Letras) como estrangeirismo, sem acento.

\section{Sugestões relacionadas à gramática}

Estão inseridos nesta categoria quaisquer problemas relacionados à gramática normativa, tais como os relacionados à regência, à concordância, ao paralelismo, à transitividade verbal etc. Seguem alguns exemplos:

- Exemplo 1 - No livro Redescobrindo o Universo Religioso, p. 44, temos: "Outros momentos da vida de Francisco poderiam ser citados como exemplo de homem de paz...". Nesta frase, a palavra "exemplo" refere-se a "momentos" e, portanto, deveria estar no plural.

- Exemplo 2 - No livro Na Ponta da Língua, p. 148, temos: "A moça entrou aflita na loja. Havia esquecido uma caixa no balcão. Uma caixa com meu gatinho, dizia ela, a toda hora. Que sorte! Estava guardadinho com a vendedora." No trecho: "Estava guardadinho com a vendedora.", "guardadinho" refere-se a "gatinho", pois está no masculino e, portanto, não pode referir-se à caixa. Mas um gato pode ser guardado? Melhor seria: "Estava guardadinha com a vendedora", com "guardadinha" se referindo à caixa. 
- Exemplo 3 - No livro Aprender Juntos Ciências, p. 46, o texto a seguir foi usado para descrever as nadadeiras: "São partes do corpo que ajudam a locomoção e o equilíbrio na água". O verbo "ajudar", no sentido de ajudar alguém (no caso, o animal) em alguma coisa, é transitivo direto e indireto. Portanto, é preciso ajustar a regência, ficando assim: "[...] que ajudam na locomoção e no equilíbrio na água.”.

\section{Sugestões relacionadas à clareza}

Essa categoria pode ser considerada crítica, de acordo com as ideias dos teóricos que estudamos no capítulo anterior. Períodos muito longos, confusos ou ambíguos dificultam o entendimento do texto e das tarefas propostas até mesmo para um adulto. Em relação à faixa etária consumidora dos produtos estudados, podemos inferir que textos que não estejam bastante claros e fáceis de compreender podem comprometer o aprendizado. Alguns exemplos de ocorrências nesta categoria:

- Exemplo 1 - No livro Redescobrindo o Universo Religioso, p. 18, o texto cita o "kipá" (tipo de chapéu usado pelos judeus) sem dar nenhuma explicação sobre o que ele seria. Seria interessante explicitar o significado da palavra "kipá", incluindo um glossário caso necessário.

- Exemplo 2 - No livro Na Ponta da Língua, p. 70, aparecem cinco palavras (que descrevem características) em um quadrado. O enunciado diz: "Escolha na caixinha uma característica para cada palavra:”. Abaixo, aparecem apenas quatro palavras. São cinco características para designar apenas quatro palavras. Melhor seria colocar a mesma quantidade de elementos a serem relacionados uns com os outros.

- Exemplo 3 - No livro Na Ponta da Língua, p. 106, o comando não está claro. O enunciado diz, fazendo referência a uma atividade anterior: "Com a lista já organizada, procure conhecer esses animais. Quais são os mamíferos? Quais são os répteis? Quais são as aves? Descubra... Conte depois para seus colegas." Essa última frase transmite a ideia de ser uma atividade oral, mas há o espaço de cinco linhas abaixo para que o aluno escreva. O que o aluno deve fazer exatamente? Categorizar os animais? 


\section{Sugestões relacionadas à coerência textual}

É parte do trabalho de preparadores e revisores garantir a coerência textual, ou seja, garantir a existência de uma relação lógica entre as ideias apresentadas. A presença de elementos contraditórios ou ambíguos em um texto pode comprometer a coerência das ideias, o que é crítico especialmente para o público consumidor na faixa etária estudada. Abaixo, alguns exemplos de problemas relacionados à coerência textual:

- Exemplo 1: No livro Aprender Juntos Ciências, p. 98, o texto é: "Com nosso corpo, percebemos o ambiente em que estamos. Sem ele, não poderíamos andar, brincar ou comer". Nessa frase, o pronome "ele" refere-se a "nosso corpo". Mas é incoerente dizer que sem nosso corpo não poderíamos andar, brincar ou comer, como se fôssemos continuar existindo sem corpo, apenas privados das ações citadas. Sem nosso corpo, não existiríamos.

- Exemplo 2: No livro Buriti História, p. 45, a contextualização de uma questão apresenta um texto de Rachel de Queiroz, no qual ela fala sobre brinquedos de antigamente. Em seguida, a pergunta: "Como eram os brinquedos no tempo em que Rachel de Queiroz era criança?”. Mas em nenhum momento no texto a autora fala de sua infância ou faz qualquer relação com seu tempo de criança. Ela poderia, inclusive, estar falando sobre um tempo que não viveu.

- Exemplo 3: No livro Na Ponta da Língua, p. 29, a questão apresenta uma receita e, em seguida, pergunta: "Que objetos da cozinha foram usados para fazer esta receita?". No entanto, como essa informação não está dada no texto, a criança não pode afirmar que objetos foram usados para fazer a receita. Ela pode somente inferir. A pergunta poderia ser: "Que objetos da cozinha você imagina que tenham sido usados para fazer esta receita?".

\section{Sugestões relacionadas à padronização}

A padronização é especialmente importante em livros didáticos, uma vez que a forma de apresentação do conteúdo pode facilitar ou dificultar o aprendizado dos alunos. Quando as unidades são 
iniciadas e finalizadas da mesma maneira ou quando os mesmos ícones são utilizados para atividades específicas, o aluno começa a estabelecer uma relação de confiança com o material, na qual ele compreende e interioriza a maneira como deve trabalhar. Seguem alguns exemplos onde poderia ter havido padronização:

- Exemplo 1 - No livro Redescobrindo o Universo Religioso, as tarefas propostas pelo livro são, geralmente, precedidas por um ícone específico. Na p. 47 o ícone não aparece.

- Exemplo 2 - O livro Na Ponta da Língua traz, em algumas questões, o lembrete de que a criança deve iniciar a frase com letra maiúscula. Em outras questões que seguem a mesma dinâmica, esse lembrete não é oferecido.

- Exemplo 3 - No livro Buriti História, as unidades de 1 a 6 são finalizadas com as partes "Para ler e escrever melhor" e "O mundo que queremos" (de forma intercalada) e as unidades de 7 a 9 finalizam na parte anterior "O que você aprendeu". Parece que foram cortadas as partes finais das últimas três unidades para que o livro não ficasse muito grande. Seria interessante padronizar a organização de todas as unidades igualmente.

\section{Sugestões relacionadas a outras ocorrências}

Estão inseridas nesta categoria questões relacionadas a omissões de termos que seriam importantes, erros de digitação, falhas de diagramação, problemas nas indicações de fontes e referências, escolhas vocabulares duvidosas, inadequações em relação à faixa etária etc. A seguir são fornecidos alguns exemplos:

- Exemplo 1 - No livro Aprender Juntos Ciências, p. 68, temos: "Na sua cidade. existe algum jardim botânico?". O ponto final após "Na sua cidade" é, provavelmente, erro de digitação.

- Exemplo 2 - No livro Na Ponta da Língua, p. 97, aparece uma história em quadrinhos iniciando a unidade. No entanto, não consta referência nem título. Todas as páginas iniciais das demais unidades trazem um título para o texto proposto.

- Exemplo 3 - No livro Redescobrindo o Universo Religioso, p. 29, temos a pergunta: "E você, sua família ou um dos colegas, o que têm feito para crescer na amizade com Deus?". A pergunta parece ser muito aberta para crianças de sete anos, pois a resposta pode se relacionar a ela mesma, à sua 
família ou a algum dos colegas. Melhor seria delimitar mais precisamente o espectro de resposta. Poderia ser: "Caso você pertença a alguma tradição religiosa, escreva abaixo o que tem feito para crescer na amizade com Deus.". ${ }^{5}$

5 Esses são somente alguns poucos exemplos das 272 ocorrências encontradas durante a análise do corpus.
Faz-se necessário esclarecer que algumas ocorrências estão relacionadas a mais de uma categoria, levando em consideração as que foram delimitadas para este estudo. Nesses casos, optouse por classificar a ocorrência levando em conta o que havia de mais problemático nela, de maneira intuitiva. Sendo assim, se um problema de pontuação interferia na clareza do texto, por exemplo, essa ocorrência pode estar em "sugestões em relação à ortografia" ou em "sugestões em relação à clareza", mas nunca em duplicidade.

Ao final dessa análise, foi possível chegar a conclusões que possibilitaram responder a alguns dos questionamentos motivadores deste estudo, e novos questionamentos surgiram. A discussão relativa aos resultados será apresentada a seguir.

Primeiramente, foi interessante perceber como os livros diferem em relação ao tratamento e à visibilidade dados aos profissionais do texto (preparadores e revisores). O livro Na Ponta da Língua (NPL), de Língua Portuguesa, não cita o nome de nenhum revisor ou preparador em sua ficha técnica. $\mathrm{O}$ livro Redescobrindo o Universo Religioso (RUR), de Religião, apresenta apenas um nome de profissional responsável pela revisão. Já os livros Aprender Juntos Ciências (AJC), de Ciências, e Buriti História (BH), de História, apresentam equipes de profissionais responsáveis pela qualidade final do texto, entre preparadores, revisores e coordenadores de revisão.

Se a quantidade de profissionais envolvidos no processo de revisão faz diferença? O senso comum nos faz pensar que sim, e o resultado deste estudo aponta nesse mesmo sentido. A quantidade de ocorrências registradas foi sensivelmente menor nos livros que contaram com uma equipe de profissionais de texto, em comparação ao que não teve revisão (ou não foi dada grande importância à atividade de revisão, já que não há nenhum nome de profissional responsável por essa atividade na ficha técnica) e ao que foi revisado por um único profissional. No total, foram encontradas 96 ocorrências passíveis de intervenção no livro NPL; 99 ocorrências no livro RUR; 41 ocorrências no livro AJC e 36 ocorrências no livro BH. Em números absolutos, a quantidade de ocorrências encontradas pode não ter tanta relevância, uma vez que os livros podem 
ter maior ou menor quantidade de páginas e as ocorrências podem ser mais ou menos graves (desde um pequeno deslize no momento da digitação, por exemplo, até questões mais problemáticas, como erros ortográficos ou gramaticais). Sendo assim, é preciso contextualizar brevemente a análise de cada uma das obras estudadas.

\section{RESULTADOS DA ANÁLISE DE DADOS}

\section{Na Ponta da Língua}

Na Ponta da Língua (NPL), de Língua Portuguesa (Access Editora), tem 157 páginas. Foram registradas 96 ocorrências para este livro, ou seja, uma média de 0,6 ocorrência por página. A maior quantidade de ocorrências (28) está na categoria "sugestões em relação à clareza", o que nos sugere o fato de que trabalhar o livro de forma a deixar claros e facilmente compreensíveis os textos, os enunciados e os comandos poderia ser a maior contribuição de uma equipe de revisores à obra. Em segundo lugar, a categoria que aparece com maior número de ocorrências (27) é "sugestões em relação a outras ocorrências", o que é natural, pois esta categoria concentra questões relativas a naturezas diversas, conforme explicitado anteriormente.

Em sua ficha técnica, o livro não apresenta o nome de nenhum revisor ou preparador de textos. Subentende-se que houve revisão sim (caso contrário, poderíamos esperar um livro com um número muito maior de ocorrências e talvez até um conteúdo não sequencial, não linear e bastante confuso, o que certamente não é o caso), mas é possível que o trabalho de revisão não tenha sido tratado como sendo estratégico para o resultado do produto final.

\section{Redescobrindo o Universo Religioso}

Redescobrindo o Universo Religioso (RUR), de Religião (Editora Vozes), tem 66 páginas. Foram registradas 99 ocorrências para este livro, ou seja, uma média de 1,5 ocorrência por página. A maior quantidade de ocorrências (29) está na categoria "sugestões em relação à ortografia", sendo que muitas delas são relativas à pontuação. A segunda maior quantidade de ocorrências (22) está na categoria "sugestões em relação à clareza" e a terceira maior (20), está na categoria "sugestões 
em relação à gramática". De acordo com esses dados, é possível inferir que este livro, especificamente, teria se beneficiado muito de um trabalho minucioso de revisão, focando primeiramente em eliminar problemas relativos à ortografia e à gramática e em um segundo momento - em melhorias que pudessem trazer mais clareza ao texto.

Em sua ficha técnica, o livro apresenta o nome de apenas um profissional de revisão. Outros revisores trabalhando no mesmo projeto, com conhecimentos, formações e perfis diferentes, certamente teriam contribuído para o resultado final da obra.

\section{Aprender Juntos Ciências}

Aprender Juntos Ciências (AJC), de Ciências (Edições SM Ltda.), tem 137 páginas. Foram registradas 41 ocorrências para este livro, ou seja, uma média de 0,3 ocorrência por página (resultado muito bom em comparação às médias dos outros dois livros, apresentadas acima). A maior quantidade de ocorrências (13) está na categoria "sugestões em relação à gramática". Em segundo lugar, a categoria que aparece com maior número de ocorrências (10) é "sugestões em relação à coerência".

Em sua ficha técnica, o livro apresenta 13 profissionais de preparação e revisão de textos (incluindo coordenador da revisão). Com base nesses dados, parece evidente concluir que a quantidade de profissionais envolvidos no trabalho é fator que contribui significativamente para a qualidade final da obra.

\section{Buriti História}

Buriti História (BH), de História (Editora Moderna), tem 119 páginas. Foram registradas 36 ocorrências para este livro, ou seja, uma média de 0,3 ocorrência por página (a mesma média alcançada pelo livro AJC, também muito boa em comparação às médias dos livros NPL e RUR). A maior quantidade de ocorrências (10) está na categoria "sugestões em relação a outras ocorrências". Em segundo lugar, a categoria que aparece com maior número de ocorrências (7) é "sugestões em relação à clareza".

Em sua ficha técnica, o livro apresenta seis profissionais (um preparador, um coordenador e quatro revisores). Apesar da quantidade de profissionais ser menos da metade dos profissionais envolvidos no trabalho de revisão e preparação do 
livro AJC, ainda é uma equipe com quantidade significativa de membros, principalmente em comparação aos dois primeiros livros analisados (NPL e RUR).

De acordo com os dados apresentados acima, podemos perceber a necessidade premente de que as diversas editoras de livros didáticos voltados para crianças repensem a importância que tem sido dada aos profissionais do texto envolvidos em seus processos editoriais. A qualidade final do produto pode melhorar? Parece evidente que sim. Mas como melhorar, de que maneira isso seria possível? Até aqui, de acordo com as informações levantadas, podemos deduzir que um dos fatores que influenciam o resultado final da obra é a quantidade de profissionais do texto envolvidos em sua produção. Contudo, certamente, existem outros.

\section{Considerações finais}

Primeiramente, é importante relembrar, nas páginas finais deste artigo, que a produção, preparação e revisão de um texto devem sempre levar em consideração o público consumidor dele. A base de um processo eficaz de comunicação é garantir não somente a emissão, mas também a recepção adequada da mensagem enviada. Sem uma recepção adequada, o processo de comunicação não se completa, não cumpre seu propósito. Da mesma maneira, o público-alvo de um produto editorial deve ser sempre estudado, a fim de garantir que o material seja estruturado da forma mais perfeita possível para atender àquele grupo específico de pessoas. Sendo assim, sugere-se que os profissionais que trabalham com edição de livros didáticos para crianças se dediquem a estudar um pouco sobre a natureza delas, de que forma elas se diferem dos adultos em sua forma de agir/ pensar e de que forma acontece a construção do conhecimento em cada faixa etária.

Foi possível conhecer um pouco, através deste estudo, sobre a natureza da criança de sete anos de idade - de forma generalizada -, o que pode ser uma base importante de informação para entender de que forma o produto final livro didático influencia seu processo de aprendizagem. A partir desse entendimento, pode-se compreender o papel de suma importância que têm os preparadores e revisores desses produtos editoriais especificamente e, com base nessa nova compreensão, talvez até promover futuros estudos ou debates acerca da prioridade que algumas editoras têm dado (ou têm deixado de dar) à atividade de revisão. 
Em relação à análise do corpus, parece ser possível concluir como dito anteriormente - que a quantidade de profissionais de texto envolvidos no trabalho é fator que contribui significativamente para a qualidade final da obra. No entanto, uma vez que não é o único, outros fatores - tais como o perfil e a formação dos profissionais de revisão, a qualidade do texto original, as condições e o processo de trabalho etc. - podem influenciar também, de maneira contundente, o resultado final do produto. Futuras pesquisas poderão demonstrar de que maneira essas outras variáveis podem ser relevantes para o resultado final dos produtos.

Por fim, embora possa parecer modismo ou clichê, é importante lembrar que as crianças são o futuro da humanidade, e um futuro bem próximo. Em muito pouco tempo, serão elas que irão comandar o mundo, espelhando o olhar que lhes damos e o cuidado que lhes provemos hoje. É preciso investir verdadeiramente na educação, em casa e na escola, sem ter como foco apenas os resultados finais (se serão ou não bem colocados no Enem, por exemplo), mas principalmente a qualidade do processo. Conhecer as crianças, quem são as crianças, a motivação por trás da maneira como elas agem, a maneira como pensam e como adquirem conhecimento é fundamental para quem trabalha diretamente com elas e também para quem trabalha criando produtos destinados a elas.

As crianças precisam ser olhadas cuidadosamente, respeitadas e tratadas de forma digna. Embora as questões relacionadas ao universo infantil sejam inúmeras, investir recursos materiais e humanos na produção dos materiais didáticos que as crianças utilizarão em seu processo de aprendizagem também faz parte desse contexto. Nesse sentido, é fundamental que qualquer editora que produza livros didáticos para crianças conte com uma equipe de profissionais de textos altamente qualificada, que possa preparar os originais e realizar a quantidade necessária de revisões para que esses materiais possam contribuir verdadeiramente com um processo de aprendizagem pleno e respeitoso. É desse processo de aprendizagem pleno e respeitoso que precisamos todos, como pais, educadores ou cidadãos; todos nós expectadores, mas também responsáveis pela construção de um país melhor, o que passa, necessariamente, pela melhoria dos processos educacionais oferecidos a todas as nossas crianças. 


\section{ABSTRACT}

This work aims to study the activities of preparing and revising the textbooks produced for the Second Grade of Elementary School. Its first part provides a brief theoretical review about developmental psychology, in order to put in context the student's cognitive development (most of them with seven years old). Its second part brings the analysis results of a corpus composed of four randomly selected textbooks, which reveal a number of instances where there could have been a previous intervention by a text reviser, prior to the final stage of making up of the texts. These instances are mainly related to spelling, grammar adequacy, textual coherence, standardization and explicitness of both content and questions as presented to the students. Finally, the key concepts are reviewed and new directions for future researches are suggested.

Keywords: Textual revision. Teaching materials. Human development.

\section{REFERÊNCIAS}

BEE, Helen; BOYD Denise. A criança em desenvolvimento. 12. ed. Porto Alegre: Artmed, 2011.

BRASIL. Ministério da Educação. Guia de livros didáticos: PNLD 2013: apresentação. Brasília, 2012. Disponível em

$<\quad$ http://www.fnde.gov.br/programas/livro-didatico/guiasdo-pnld/item/3773-guia-pnld-2013-\%E2\%80\%93-ensinofundamental $>$. Acesso em: 16 abr. 2015.

CARVALHO, Regina; ROSSI, Natércia. Na ponta da língua. 7. ed. Rio de Janeiro: Access, 2010.

MODERNA, Editora. (org.) Projeto Buriti: história. 3. ed. São Paulo: Moderna, 2013.

MOTTA, Cristiane. Aprender juntos ciências, $2^{\circ}$ ano: ensino fundamental. 4. ed. São Paulo: Edições SM, 2013.

PEREIRA, Marcos Sidney. Redescobrindo o universo religioso: ensino fundamental; livro do estudante, volume 2. 5. ed. Petrópolis: Vozes, 2011. 
ESPUC

BELO HORIZONTE - N. 26 - 2015

PIAGET, Jean. O juízo moral na criança. 4. ed. São Paulo: Summus, 1994.

VIGOTSKI, Liev Semiónovitch. Pensamento e linguagem. 4. ed. São Paulo: Martins Fontes, 2008. 